\section{It is never too late to learn to work: An experience with adults with Down's syndrome developed in Majorca, Spain}

\section{Juan Perera}

\author{
Director of the Prince of Asturias Centre of \\ the Down Syndrome Association of the \\ Balearic Islands. \\ Chairman of the Scientific Board of EDSA \\ (European Down Syndrome Association).
}

\begin{abstract}
This paper describes the establishment of a 'state of the art' commercial greenhouse, where all the horticulture is carried out by adults with Down's syndrome. These adults grew up at a time when the educational opportunities and social experiences available to them were extremely limited. This project has shown them capable of learning a range of new skills to a high level and it has brought them dignity, independence and enhanced their self-esteem. A video tape of the project is available from the author.
\end{abstract}

The paper was presented at the EDSA Schweiz Symposium on Down's syndrome held in Basel, Switzerland, October 1993.

(C) 1993, 1999. The Down Syndrome Educational Trust Down Syndrome Research and Practice 1994, 2 (1) 36-39
It is fantastic to observe how many young persons with Down's syndrome have reached levels of personal independence, linguistic communication, awareness and analysis of their own limitations, completely unthinkable until a short time ago. Their example opens up a new horizon of hope, and is a stimulus for many persons with Down's syndrome to improve and progress in their capacities and abilities until they achieve a full and true integration into their academic, social and work environment; and for teachers not to put a ceiling on their achievements.

But in the hearts of many parents a feeling of disappointment may also arise because the experience they have lived or are living with their child has been very different. Moreover, they think that they have not brought their children up correctly, that they have not provided the appropriate means, that they have not been well advised, that they have not gone to the right school ... for the simple reason that they have not achieved the results which they now see in others. And this is completely false.

It is good that persons with Down's syndrome who express themselves normally, who are taking further education or who are planning their university studies should appear in public. But not all people with Down's syndrome are like this, or can reach these levels. Because it must not be forgotten that among persons with Down's syndrome the same thing happens as with normal people: there are people who are more gifted and others who are not so bright. In a graph of normal distribution, the average is the most common score in a group, and the range around this average, on the right and on the left, is what is known as 'normality', that is to say $70 \%$ of the cases. And at each end are the remaining $15 \%$ of the cases who exceed, either by excess or deficiency, the criteria of normality.

TV, Congresses and the news media have presented cases with Down's syndrome who do not represent the 'normality' of Down's syndrome. They are especially gifted cases and they have often had at their disposal educational means which are not within everyone's reach. Real cases, and it is positive that they are shown because - I repeat - they serve as a stimulus and incentive to help break negative social patterns and because they aid the integration of children with Down's syndrome.

'Normality' is, however, a relative term. 'Normality' has also changed in Down's syndrome. Progress in genetics and neurobiology, early intervention, learning and behavioural psychology and modern pedagogical techniques have managed to better develop each child's potential. 'Normality' in Down's syndrome has raised its level. Today - following the correct techniques - most children are, for example, able to read and write fairly fluently, something completely unthinkable just ten years ago.

But, beware! With the best intention we forget that there is a cerebral pathology which is the consequence of the chromosome abnormality present in persons with Down's syndrome. And that this pathology varies greatly from one person to another and it also affects in a different measure their capacity for learning and adapting to their environment.

Educational programmes on language, reading, writing, work training, etc., are directed at that $70 \%$ which constitutes normality within Down's syndrome, and we have already 


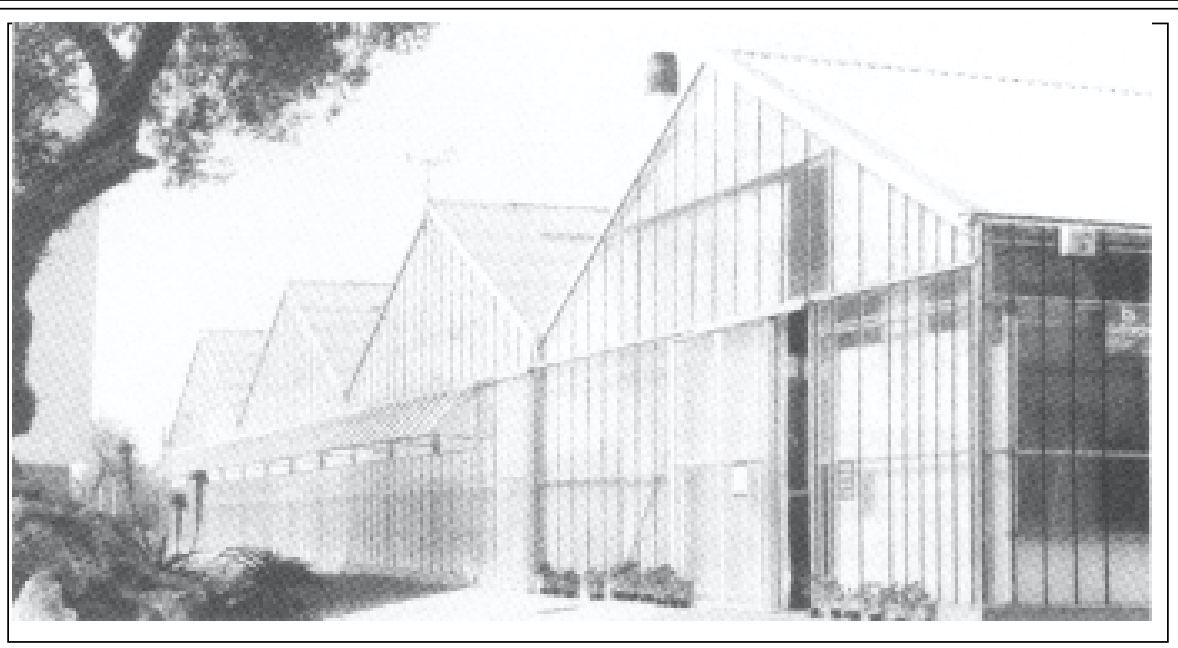

The greenhouse in Majorca

said that there are $15 \%$ above (who are obviously those who are outstanding for their brilliant results) and another $15 \%$ below who are hardly ever mentioned.

And I wish to speak to you about that group, that least gifted, most difficult 15\%, who never achieve brilliant results; and to present to you an experience which we have carried out at the Down Syndrome Association of the Balearic Islands (ASNIMO) in Majorca (a beautiful Mediterranean island).

Our project was sponsored by the PETRA PROGRAMME of the European Community and by the ONCE Foundation and is centred around adults with Down's syndrome, who were already grown-up when they came to ASNIMO, the majority from deprived socio-economic backgrounds, who did not benefit from early intervention or modern psychopedagogical techniques, who express themselves with great difficulty, who cannot read, who if they do not sign their name every day, forget how to sign, and who, if we go by the psychological tests, show intelligence quotients of less than 50 .

Well then, it so happens that these young persons with Down's syndrome, who appeared useless, who carried out repetitive, senseless tasks and who were not given the opportunity to demonstrate their capacity, are working in the Special Employment Centre, subject to normal employment regulations, and that they are the only workers of a company called 'SEMPRE VERD' S.L. (EVERGREEN), which has built and operates in Majorca a greenhouse of $3,500 \mathrm{~m}^{2}$ dedicated to the cultivation of ornamental tropical plants with an output of 30,000 plants per month.

In our project there are three underlying principles:

1) It is never too late for people with Down's syndrome to learn. Even though they are grown-up, even though they have not been to school, even though they show a serious impairment.

2) Non intervention means retardation. Or, put another way, intervention must be constant, systematic, appropriate and based on effective and personal motivation.

3) Persons with Down syndrome of any age and condition can work:

\section{IF: we study their specific capabilities and abilities. IF: we train them correctly. IF: we adapt the jobs to their specific abilities. IF: we give them the opportunity to do so.}

I should like to stop at this stage in order to explain this point to you a little more. I have said:

\section{1) IF: we study their specific capabilities and abilities.}

- We were faced with a serious problem: we had 35 young persons of working age with no training whatsoever.

- These young persons with Down's syndrome showed common characteristics: difficulty in expressing themselves, lack of responsibility to continue with a task, lack of memory.

We then tried with different types of jobs:

- Woodwork (olive wood), leather work, ceramics, assembly work, gardening ...

And we noticed that certain individuals:

- Were especially productive at gardening.

- And that, furthermore, they enjoyed their work.

And in this way we selected the present group of workers.

\section{2) IF: we train them correctly.}

How to train them? That was the problem! We joined the PETRA PROGRAMME of the European Community. This was the process:

A) With the help of teachers from the 'LA MENITRE' (National Centre for Horticultural Promotion in France) we made a list of jobs carried out in the greenhouse.

B) We then selected from this list the jobs which, theoretically, the training team thought persons with Down's syndrome could carry out in a greenhouse.

C) We made, put into order and systematised our teaching material (file cards, practice, experiences) to teach the pupils to carry out these tasks. 
D) Using learning psychology and behaviour modification techniques, we patiently taught these young people each of the tasks pertaining to a greenhouse. They learned them well. This was our first big surprise. This lasted for two and a half years.

\section{3) IF: we adapt the jobs to their specific capacities and make up for their deficiencies.}

We have made countless adaptations:

- Lowering the height of the work benches.

- Adapting the irrigation system.

- Marking the trolley paths with adhesive tape.

- Protecting the glass with bars.

- Teaching them to work with gloves.

- Protecting and designing new tools: purchasing shears, etc.

- Designing countless gadgets to make up for personal deficiencies. For example:

* For placing the plant in the centre when transplanting it.

* For taking cuttings.

* For planting groups of plants.

\section{4) IF: we give them the opportunity to do so.}

And it was not easy to give them this opportunity.

- INSERSO, which is the official body in Spain responsible for the disabled, did not want to give us the cards necessary to register them at the Employment Office because they said, literally "Mongols cannot work".

- Some families refused to allow their children to work.

And so the work began. They are all on the permanent staff and earn the minimum basic wage plus two annual bonus payments. They have lunch at work and they have adapted perfectly to working life.

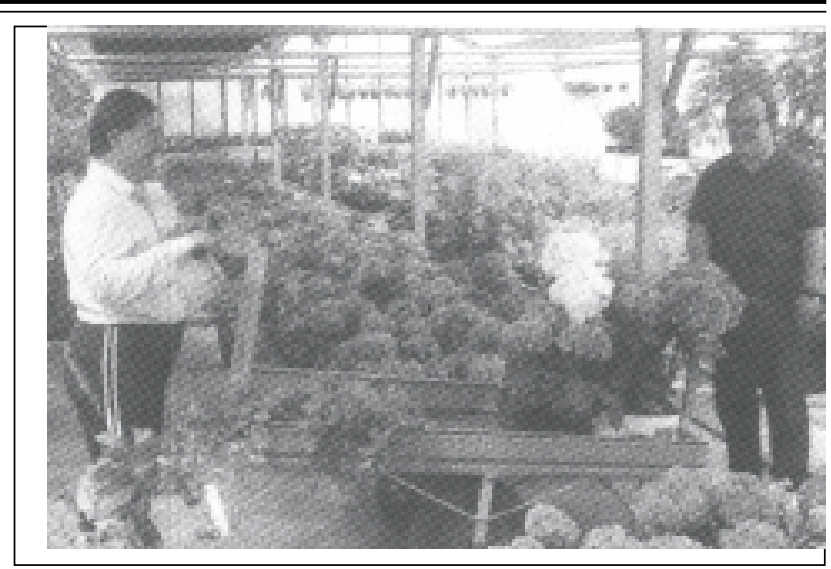

At work in the geenhouse

Our workers, at a slower rate and under constant supervision, today carry out all the usual greenhouse tasks: sowing, pricking-off seedlings, transplanting, ringing, etc.... and they carry them out efficiently and correctly. Their professional capacity and work motivation improves every day.

Our project is continuing towards the full working integration of some of our young people into an ordinary company. At the present moment three young persons with Down's syndrome are working successfully in normal gardening companies through the 'supported employment' system.

But the most important thing is that the lives of these young people have been transformed. They leave home every morning to go to work like their brothers and sisters, they are proud of their work, they feel useful, they know that their wages are the fruit of their effort, they share joys and sorrows with their workmates, they have friends, they watch 'their' plants grow ... and I can assure you that there are no hands more tender than these to make them grow.

You know that at present the life expectancy of persons with Down's syndrome has greatly increased. The parents of

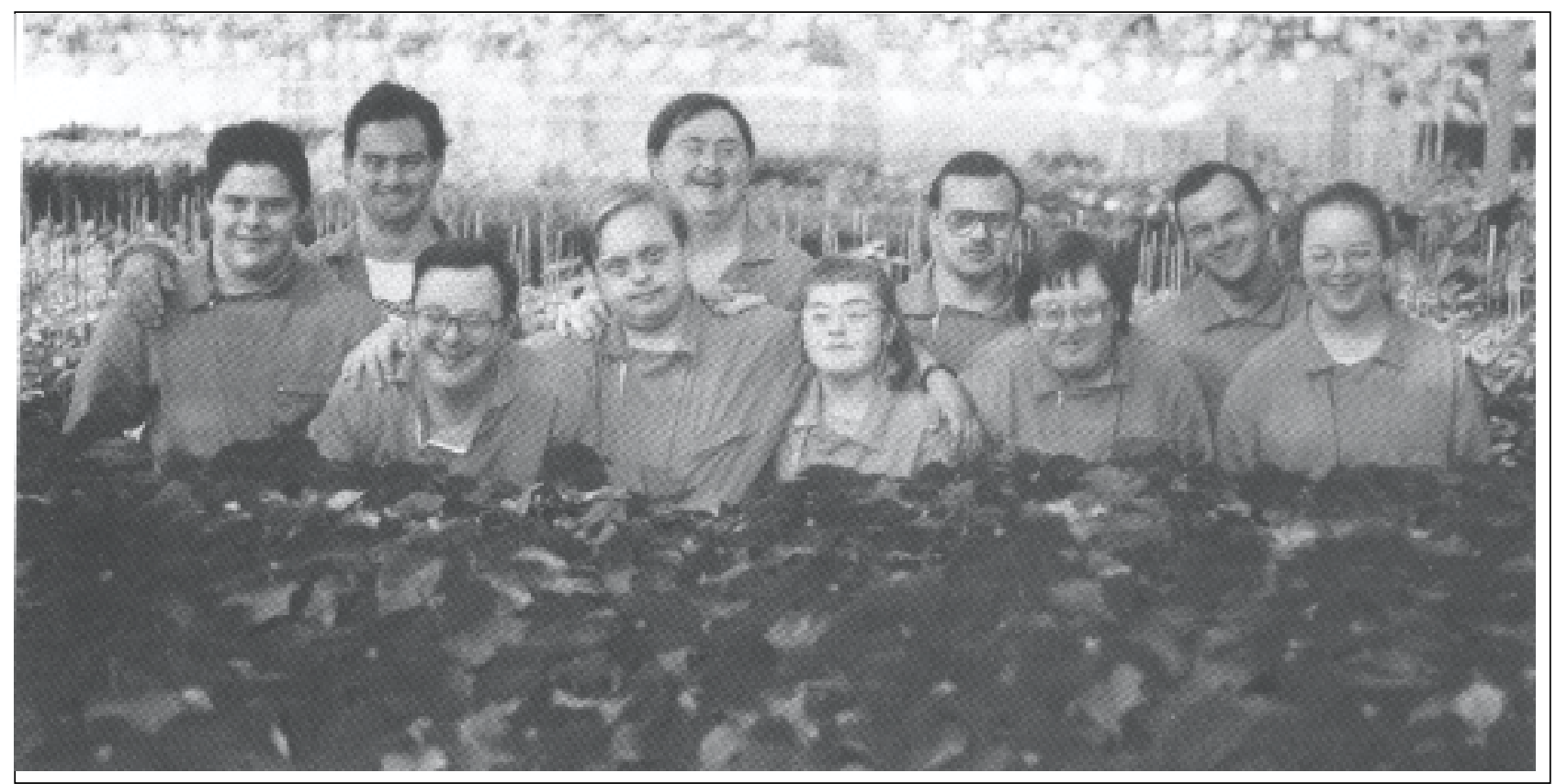

Some of the young people who work in the greenhouse 
some of these young people have died and their brothers and sisters cannot look after them.

Our project has extended towards giving them greater personal autonomy and a more independent way of life in small warden-controlled residences. Within the framework of a positive quality of life the mini-residence offers them, in the absence of their families, security, stability and the opportunity to maintain effective relationships.

Our Association has tried to solve this problem by creating permanent, stable centres - the mini-residence is their home
- where these young people live as a family in an increasingly independent way.

\section{EMPLOYMENT AND PEOPLE WITH LEARNING DISABILITIES}

A one-day workshop for anyone working with or caring for people with learning disabilities.

28th June 1994

at The Sarah Duffen Centre, University of Portsmouth

Workshop co-ordinator:

Tom Bush

Nurse Teacher

Tor and South West College of Health.

Sessions include:

Employment Opportunities - The British Experience

Advanced Industrial Training

Employment Opportunities - The Danish Experience

How to develop work alternatives

For details, contact: The Sarah Duffen Centre, University of Portsmouth, Belmont Street, Southsea, Hants, P05 1NA. Tel: 0705 824261, Fax: 0705824265.

\section{NORTHERN REGION NATIONAL PORTAGE CONFERENCE}

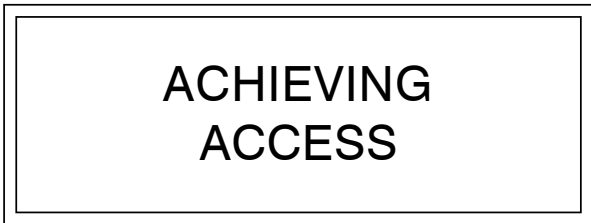

Friday 23rd to Sunday 25th September 1994

at

Leeds University, Leeds, Yorkshire

Conference Co-ordinator

Krystyna Johnson

Leeds City Portage Service

The Blenheim Centre

Crowther Place

Leeds, LS6 2ST.

Tel: 0532429111 